\title{
Prevalence and Knowledge about Genital and other Warts among Students in Sulaimani Polytechnic University: A cross-sectional study
}

\author{
Burhan Karadaghy \\ Community Health Department \\ Technical College of health \\ Sulaimani Polytechnic University \\ Sulaimani, Iraq \\ Burhan.karadakhy@spu.edu.iq
}

\author{
Niaz Mustafa Kamal \\ Anesthesia Department \\ Technical college of health \\ Sulaimani Polytechnic University \\ Sulaimani, Iraq \\ niaz.kamal@spu.edu.iq
}

\author{
Nasih Othman \\ Kurdistan institute for Strategic Studies \\ and Scientific Research \\ Sulaimani, Iraq \\ nasih.othman@kissr.edu.krd
}

\begin{abstract}
Genital warts and other warts are an epidermal manifestation attributed to the epidermotropic human papillomavirus (HPV) some of which have been linked directly to an increased neoplastic risk in men and women. According to our knowledge, research is scarce and little is known about this condition in Sulaimani province. A cross-sectional study was carried out from $1^{\text {st }}$ April to $30^{\text {th }}$ May 2018 including 441 undergraduate students aged between 1830 years belonging to the health and non-health colleges of Sulaimani Polytechnic University. Data were obtained on the knowledge about genital warts through self-administrated questionnaire from the students. Data were analyzed using STATA 11. The mean age of the participants was 21.3 years. Hand warts were the commonest types among participants (31\%). Knowledge score ranged from 0 to 9 , was not normally distributed with a median of zero (IQR 0-22), $89 \%$ of the students had very low knowledge score. Knowledge score correlated with socio-demographic parameters were significantly higher in health students $(P<0.001)$; outside Sulaimani city $(P=0.01)$ and students aged 2130 ( $P<0.001)$. In general, it is highlighting the need for communication and education among students in order to overcome the lack of knowledge about genital warts and HPV infection. It also might reflect higher health consciousness among Sulaimani university students.
\end{abstract}

Keywords: Warts, Genital, Sulaimani, Papillomavirus, Knowledge.

\section{INTRODUCTION}

Condylomata acuminate, or genital warts, are lesions or a small lumps that develop around genital area caused by human papillomavirus (HPV) infection which is usually causing a range of manifestation from asymptomatic, latent infection to the typical exophytic cauliflower-like of the genital epidermal layer which they are usually passed by sexual contact [1]. Non-genital warts are more prevalent, is a benign and usually self-limited infection. Common warts are most often seen on the hands and present as skin-colored papules. Flat warts are most often seen on the backs of the hands and on the legs. They appear as slightly elevated, small plaques that are skincolored or light brown. Plantar warts occur on the soles of the feet and look like very thick calluses [2]. Among more than 200 different types of HPV discovered so far, with approximately 40 different subtypes are belonging to cause infection of the genital area, cause both benign and malignant lesions[3] The Human papillomavirus (HPV) is prevalent sexually transmitted virus worldwide, and it is estimated that over $50 \%$ of sexually active men and women at a younger age have been infected with one or more genital HPV [4]. These can be subdivided into low risk, intermitted risk, and high risk, depending on the likelihood of generating intraepithelial dysplasia [5]. The only two types are about $90 \%$ HPV types 6 and 11 are likened to cause benign anogenital warts (GWs) and recurrent respiratory papillomatosis (RRP) [6]. In addition, between 13-18 HPV strains which have a high risk for neoplastic conversion and the commonly detected types HPV-16 and HPV- 18 are strongly associated with cervical dysplasia and are therefore considered to be a high risk [7, 8]. HPV types 31, 33, 45, 51, 52, 56, 58, and 59 are typically thought to be of intermediate risk since they are often found in association with squamous neoplasms. Furthermore, have been rarely linked to cervical SCC [1]. Both men and women are affecting by genital warts but the affecting is slightly higher in men compared to women [9]. The highest prevalence rate of genital warts infection is discovered among adults age group 18-28 years old [8]. The quadrivalent HPV vaccine, which is active against HPV 6, 11, 16 and 18, is significantly effective in preventing HPV and reduce genital warts in both male and female [10]. As the disease is more common among young age groups and their age carries high risk. The purpose of the study is to assess awareness and knowledge about genital warts infection among students at Sulaimani Polytechnic University, Iraq, Kurdistan.

\section{METHODS AND MATERIALS}

This cross-sectional study was conducted among students of the polytechnic university in Sulaimani city from $1^{\text {st }}$ April to $30^{\text {th }}$ May 2018 on (441) undergraduate students aged between 18-30 years belonging to medical, engineering, management and computer information technology were studied in these colleges. The polytechnic university has a large campus comprised of four technical colleges. A convenient sample size of (441) 
students was chosen because this is conservative and adequate when the proportion of participants is not known. The simple random sampling method was used to select one or two classes from each college. The sample was selected from the list of students in each selected class using systematic random sampling. A pre-tested questionnaire was used in this research. A pilot study was done prior to this investigation to validate the questionnaire. The questionnaire was divided into two main parts: part one includes the respondents' sociodemographic profiles and Part two involves questions to assess their knowledge on genital warts. Privacy and confidentiality were respected and questionnaires were anonymized. The data was collected via a selfadministrative questionnaire with students. Answering the questionnaire lasted 10-15 minutes after explaining the aim of the study and obtaining informed consent. Apart from the interview time, there was no harm or inconvenience to the students. The study was approved by the ethics committee of the Technical College of Health. In addition, permission was taken from each college were the data was collected. Data were entered into EpiData (version 3.1) and analyzed by Stata (version 11). Demographic variables were described using frequencies and percentages. While for numeric variables median was used for those not normally distributed, mean and the standard deviation was used for those normally distributed variables. Questions on Knowledge were scored for determining the levels. A knowledge summary score was computed by assigning one point for each correct response and zero points for each wrong and 'don't know' answers. Points were summed to create a knowledge summary score. Differences in knowledge across provider type were evaluated using a Chi-square test where a $P<0.05$ was considered statistically significant.

\section{RESULTS}

The selected sample was 450 students, of which 441students completed the questionnaire, giving a response rate of $98 \%$. The mean age of the students was 21.3 years (SD 2.6) with the rage of 18-30 years. Table 1 shows main characteristics of the participants. There were more female participants (58\%) higher than male students (42\%). Majority of the participants were single (85\%), and a higher proportion of the participants were from inside of Sulaimani (60\%). Most (39\%) of the participants were in their second year in the university. the number of non-health science participants was higher (65\%) compared to health science (34\%). Of the (28.6\%) participants had warts in past and $(5.5 \%)$ have warts during the study.
Table 1: Socio-demographic data of the study participants.

\begin{tabular}{|c|c|c|}
\hline Variable & $\begin{array}{l}\text { Frequency } \\
(\mathrm{N}=441)\end{array}$ & $\begin{array}{c}\text { Percentage } \\
\%\end{array}$ \\
\hline \multicolumn{3}{|l|}{ Age in year } \\
\hline$<20$ & 196 & 44.8 \\
\hline $21-25$ & 198 & 45.2 \\
\hline$>26$ & 44 & 10 \\
\hline \multicolumn{3}{|l|}{ Gender } \\
\hline Male & 184 & 41.9 \\
\hline Female & 255 & 58.1 \\
\hline \multicolumn{3}{|l|}{ Marital state } \\
\hline Single & 375 & 85.4 \\
\hline Married & 59 & 13.4 \\
\hline Divorce & 5 & 1.2 \\
\hline \multicolumn{3}{|l|}{ Residence } \\
\hline Inside sulaimani & 265 & 60.1 \\
\hline Outside sulaimani & 176 & 39.9 \\
\hline \multicolumn{3}{|l|}{ Education levels } \\
\hline First year & 97 & 22 \\
\hline Second year & 173 & 39.2 \\
\hline Third year & 97 & 22 \\
\hline Fourth year & 74 & 16.8 \\
\hline \multicolumn{3}{|l|}{ Field of the study } \\
\hline Health sciences & 150 & 34.1 \\
\hline Non-health sciences & 291 & 65.9 \\
\hline \multicolumn{3}{|l|}{$\begin{array}{l}\text { Students had warts in } \\
\text { past }\end{array}$} \\
\hline Yes & 126 & 28.6 \\
\hline No & 315 & 71.4 \\
\hline \multicolumn{3}{|l|}{$\begin{array}{l}\text { Students have warts } \\
\text { during the study }\end{array}$} \\
\hline Yes & 24 & 5.5 \\
\hline No & 416 & 94.5 \\
\hline
\end{tabular}

Figure 1 shows the prevalence of warts during the survey which was $5.5 \%$ among the participants of which 5\% were hand warts and $0.5 \%$ was genital warts. Past history of warts (ever having warts in the past) was positive in $28.6 \%$ of the participants $(26.3 \%$ had hand warts and $2.3 \%$ had warts in another area).

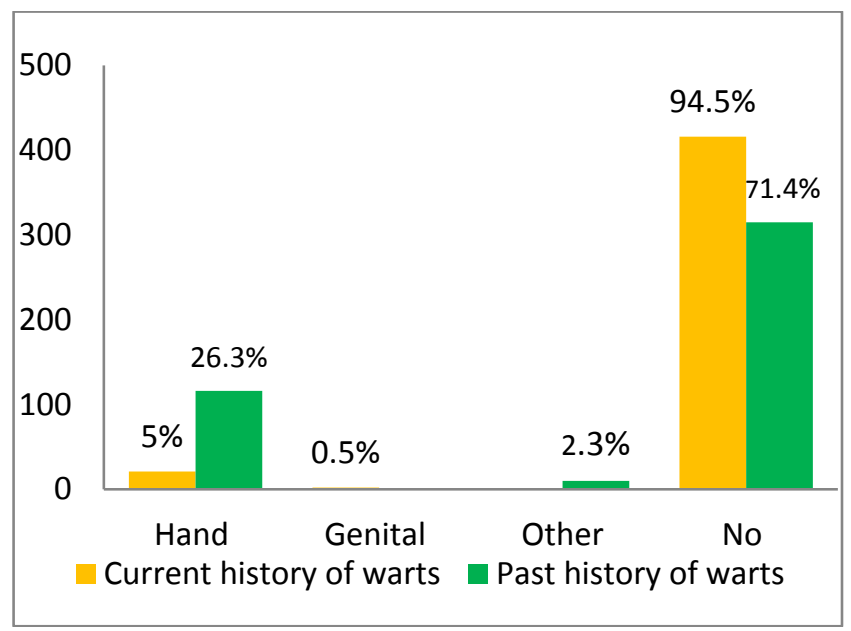

Figure1: Prevalence types of warts among the participants.

We analyzed types of warts by gender, residence, marital state and age (Table 2). Female students with different types of warts were higher $(57.4 \%)$ compare to male students (42.6\%), this difference was not statistically significant $\mathrm{P}=0.8$. Married and unmarried students have similar percentages (12.4\% VS.15.5\%) of having different types of warts. Participants from inside city who 
have warts were $(60.5 \%)$, while $(39.5 \%)$ of participants from outside city have warts, this difference was statistically significant $\mathrm{P}=0.01$. The prevalent of warts among students aged $<20$ and between $21-25$ years who have warts were $(41.9 \%, 48.8 \%)$ respectively which were higher than those aged 26 years and over (9.3\%), this difference was not statistically significant $\mathrm{P}=0.9$.

Table 2: Different types of warts by gender, residence, marital state and age.

\begin{tabular}{|c|c|c|c|c|}
\hline \multirow[t]{2}{*}{ Parameters } & \multicolumn{2}{|c|}{ Warts condition } & \multirow{2}{*}{$\begin{array}{c}\mathbf{P} \\
\text { value }\end{array}$} & \multirow{2}{*}{$\begin{array}{l}\text { Chi- } \\
\text { square }\end{array}$} \\
\hline & Yes & No & & \\
\hline \multicolumn{3}{|l|}{ Gender } & \multirow{3}{*}{0.8} & \multirow{3}{*}{0.03} \\
\hline Male & $55(42.6 \%)$ & $129(41.6 \%)$ & & \\
\hline Female & $74(57.4 \%)$ & 181(58.4) & & \\
\hline \multicolumn{3}{|l|}{$\begin{array}{l}\text { Marital } \\
\text { state }\end{array}$} & \multirow{3}{*}{0.4} & \multirow{3}{*}{0.7} \\
\hline Married & $16(12.4 \%)$ & $113(87.6 \%)$ & & \\
\hline Unmarried & $48(15.5 \%)$ & $262(84.5 \%)$ & & \\
\hline \multicolumn{3}{|l|}{ Residence } & \multirow{3}{*}{0.01} & \multirow{3}{*}{0.9} \\
\hline Inside & $\begin{array}{c}78 \\
(60.5 \%)\end{array}$ & $187(60 \%)$ & & \\
\hline Outside & $51(39.5 \%)$ & $125(40 \%)$ & & \\
\hline \multicolumn{3}{|l|}{ Age in year } & \multirow{4}{*}{0.9} & \multirow{4}{*}{0.6} \\
\hline$<20$ & $54(41.9 \%)$ & $142(45.9 \%)$ & & \\
\hline $21-25$ & $63(48.8 \%)$ & $135(43.7 \%)$ & & \\
\hline$>26$ & $12(9.3 \%)$ & $32(10.4 \%)$ & & \\
\hline
\end{tabular}

shows the knowledge of the participant's students about genital warts and HPV infection while exploring the general knowledge of students regarding warts 375 students reported that they had already heard of genital warts. Of the participants, 56 were aware that HPV causes genital while higher numbers 206 was answered no and 173 were answered don't know. Of the 5 of participants have knowledge of HPV affected male, 22 affected female and 87 affected both genders. Lower numbers 82 of the students were aware of HPV transmitted from infected person to healthy person out of 440 students. According to the mode of transmission, 6 students stated a cough and sneezing and, 10 selected shaking hand and hugging, and 97 of the participants have information that HPV is transmitted by sex with multi-partner, while the rest 327 stated don't know. Almost, 45 participants have known HPV have a vaccine while the rest answer no and don't know. The other knowledge parameters were presented in the table.
Table 3: Parameters of Knowledge of the participants

\begin{tabular}{|c|c|}
\hline Parameters & $\begin{array}{l}\text { Frequency } \\
(\mathrm{N}=441)\end{array}$ \\
\hline \multicolumn{2}{|l|}{ Have you heard about warts } \\
\hline Yes & 375 \\
\hline No & 66 \\
\hline \multicolumn{2}{|l|}{ Have you heard about HPV } \\
\hline Yes & 56 \\
\hline No & 209 \\
\hline Don't know & 173 \\
\hline \multicolumn{2}{|l|}{$\begin{array}{l}\text { Do you know that HPV causes } \\
\text { genital warts }\end{array}$} \\
\hline Yes & 56 \\
\hline No & 219 \\
\hline Don’t know & 165 \\
\hline \multicolumn{2}{|l|}{$\begin{array}{l}\text { Type of gender can be affected by } \\
\text { genital warts }\end{array}$} \\
\hline Male & 5 \\
\hline Female & 22 \\
\hline Both & 87 \\
\hline Don't know & 327 \\
\hline \multicolumn{2}{|l|}{$\begin{array}{l}\text { Genital warts transmitted from } \\
\text { infected person to a healthy person }\end{array}$} \\
\hline Yes & 82 \\
\hline No & 67 \\
\hline Don't know & 291 \\
\hline \multicolumn{2}{|l|}{ Mode of transmission of HPV } \\
\hline A cough or sneezing & 6 \\
\hline Hacking and shaking the hand & 10 \\
\hline Genital skin to skin contact & 97 \\
\hline Don't know & 327 \\
\hline \multicolumn{2}{|l|}{$\begin{array}{l}\text { Female with HPV infection can be } \\
\text { transmitted to male }\end{array}$} \\
\hline Yes & 84 \\
\hline No & 12 \\
\hline Don’t know & 345 \\
\hline \multicolumn{2}{|l|}{$\begin{array}{l}\text { Male with HPV infection can be } \\
\text { transmitted to the female }\end{array}$} \\
\hline Yes & 73 \\
\hline No & 10 \\
\hline Don't know & 357 \\
\hline \multicolumn{2}{|l|}{ Can HPV causes cancer of } \\
\hline Cervical & 17 \\
\hline Anal & 2 \\
\hline Penile & 18 \\
\hline Female and male genital cancer & 20 \\
\hline Others genital & 4 \\
\hline Don’t know & 378 \\
\hline \multicolumn{2}{|l|}{$\begin{array}{l}\text { Is there any vaccination for HPV } \\
\text { infection }\end{array}$} \\
\hline Yes & 45 \\
\hline No & 57 \\
\hline Don’t know & 339 \\
\hline
\end{tabular}

The most common source of information on warts was from television/internet and medical staffs (59\%), followed by during the study (9\%), television and internet (7\%) respectively while $(14 \%)$ were not heard about it (Figure 2). 


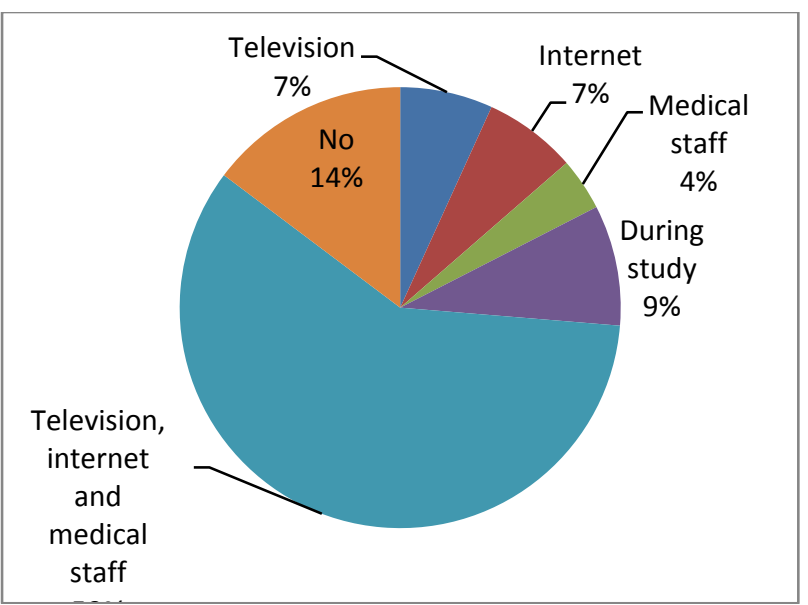

Figure 2: Frequency distribution of information source about genital and other warts.

The genital warts score ranged from $0-9$ on a 100 scale with a median of zero and Interquartile range of $0-22$. The knowledge score was then categorized to 3 levels as shown in Table 4. Majority 384 (88.5\%) of the students had very poor knowledge score. Overall, only 16 (3.7\%) of the students had good information about genital warts out of 434 students.
Table 4: Distribution of knowledge levels of the participants.

\begin{tabular}{|c|c|c|}
\hline Knowledge levels & Score & \% \\
\hline Good $\left(70 \%^{+}\right)$ & 16 & 3.7 \\
\hline Fair $(50-69 \%)$ & 34 & 7.8 \\
\hline Poor below $50 \%$ & 384 & 88.5 \\
\hline Total & $\mathbf{4 3 4}$ & $\mathbf{1 0 0 \%}$ \\
\hline
\end{tabular}

Table 5 shows the association between knowledge levels and socio-demographic data. The findings indicate that there was the statistically significant difference between a field of the study, residence, and age of the respondents. Health science $(10.7 \%)$ have higher knowledge compared to non-health science (0\%) this difference was statistically significant $\mathrm{P}=<0.0001$. Outside residence participants have more information about genital warts (6.9\%), while inside participants residence has poor (90\%) this difference was statistically significant $\mathrm{P}=0.01$. Married students (8\%) were more awareness than unmarried students (3\%), this difference was not statistically significant $\mathrm{P}=0.1$. Respondents aged 21-25 (3.6\%) and 26 over (14\%) have more information compared to those aged 20 below $(0.5 \%)$ this difference was statistically significant $\mathrm{P}=<0.0001$.

Table 5: Comparison of knowledge levels with socio-demographic variables

\begin{tabular}{|c|c|c|c|c|c|}
\hline Variable & Good & Fair & Poor & Chi-square & P value \\
\hline Gender & & & & \multirow[b]{3}{*}{0.8} & \multirow[b]{3}{*}{0.6} \\
\hline Male & $5(2.8 \%)$ & $15(8.3 \%)$ & 161(88.9\%) & & \\
\hline Female & $11(4.4 \%)$ & $19(7.6 \%)$ & $221(88 \%)$ & & \\
\hline \multicolumn{4}{|l|}{ Field of the study } & \multirow[b]{3}{*}{49.5} & \multirow[b]{3}{*}{$<0.0001$} \\
\hline Health science & $16(10.7 \%)$ & $22(14.8 \%)$ & $111(74.5 \%)$ & & \\
\hline Non-heaa lth science & $0(0 \%)$ & $12(4.2 \%)$ & 273(95.8\%) & & \\
\hline \multicolumn{4}{|l|}{ Residence } & \multirow[b]{3}{*}{8.6} & \multirow[b]{3}{*}{0.01} \\
\hline Inside sulaimani & $4(1.5 \%)$ & $22(8.5 \%)$ & $234(90 \%)$ & & \\
\hline Outside sulaimani & $12(6.9 \%)$ & $12(6.9 \%)$ & $150(86.2 \%)$ & & \\
\hline \multicolumn{4}{|l|}{ Marital state } & \multirow[b]{3}{*}{4.1} & \multirow[b]{3}{*}{0.1} \\
\hline Married & $5(8 \%)$ & $6(9.5 \%)$ & $52(82.5)$ & & \\
\hline Unmarried & $11(3 \%)$ & $28(7.6 \%)$ & $330(89.4 \%)$ & & \\
\hline \multicolumn{4}{|l|}{ Age in year } & \multirow[b]{4}{*}{22.1} & \multirow{4}{*}{$<0.0001$} \\
\hline$<20$ & $1(0.5 \%)$ & $18(9.3 \%)$ & $175(90.2 \%)$ & & \\
\hline $21-25$ & $7(3.6 \%)$ & $15(7.7 \%)$ & $172(88.7 \%)$ & & \\
\hline$>26$ & $6(14 \%)$ & $1(2.3 \%)$ & $36(83.7 \%)$ & & \\
\hline
\end{tabular}

\section{DISCUSSION}

This study was conducted to assess the knowledge of multidisciplinary students regarding genital warts and HPV infection in Sulaimani Polytechnic University. Overall, the study revealed that hand warts (31\%) are the most common type of warts among the student's generally, the result of the prevalent type in our study was similar (33\%) to the result of Indian study [11]. The students had very poor knowledge about genital warts and HPV infection (88.5\%), which is in accordance with the studies which were done at the University of Lagos in Nigeria and United state [12, 13]. The majority of the students (375 out of 441) were heard about warts in general. It is also of great concern that, in this study, only a small group 56 of the students had heard about HPV infection, our findings are in contrast with this study [14]. According to our results, only 56 students out of 441 know that HPV causes genital wart. Similarly, a study in Nigeria reported that less $10 \%$ of students were aware of HPV infection causes the infection [12]. The study reveals that the main source of information about genital warts and HPV infection was through television, internet, and medical staffs, these findings were similar to studies in Florida and Malaysia [14-16]. Television, radio, and internet were electronic mass media commonly utilized by young adults for their leisure and entertainment. With respect to awareness about HPV affecting which type of gender, only 87 students stated that HPV infected both men and women. Similarly, a study in Pakistan reported that both gender male and female were affected by HPV [17]. In addition, only 82 students have information that genital warts can be spread from an infected person to a healthy one. It is similar to the study which was done at Students University in Malaysia[16]. Furthermore, when students where asked questions about the route of transmission, 6 of the students answered a cough and 
sneezing, 10 of them statted hugging and shaking hand and only 97 of the students who were aware of genital warts and HPV infection is sexually transmitted disease, while 327 of the student said they did not know how HPV is transmitted. Likewise, an international comparison study supported our result[18]. In our study when the students were asked whether genital wart and HPV can cause cancers, the majority of them stated that they didn't know about it. Only 17 stated that HPV cause cervical, 2 and 18 students selected anal and penile respectively. Is corresponding with a study which was performed among female students in Taiwan[19] and on the contrary with a study in Colombia, showed that the respondents have higher knowledge about the connection between HPV and cancer[20]. The present study reported that 339 students they don't know about any vaccination for the infection and 57 students stated that there is no vaccine to prevent the infection. It could be due to the fact that they had no or very little knowledge about the vaccination. This finding is in accordance with previous Pakistan study which has demonstrated that people generally do not know about HPV vaccine[17]. Health science students have the major source of information about genital warts and HPV infection compare to non-health science. It is similar to the study in USA [13] which showed that health science students have more information about genital warts. The study finds that 154 students reported that HPV can transmit from male to female and vise versa. They think both male and female can spread the infection to each other [21]. We have noticed that the level of knowledge about HPV was significantly associated with the field of study $\mathrm{P}<0.0001$, the age of the students $\mathrm{P}$ $<0.0001$ and residents of the students $\mathrm{P}=0.01$. The students of the health science department were more aware of genital warts and HPV compare to non- health science. The knowledge level was better among the students with higher age. Awareness of the condition was higher in older participants (14\%) than younger (3.6\%). The students who lived outside the city were having a higher knowledge than those who lived inside the city, this could be due to the availability of different entertainment places which make them busy with trivial things or could be due to their willingness to compete with the students inside the city. The findings are corresponding with the studies which were performed in Malaysia and Greece [22-24]. Based on gender we found no difference in HPV awareness, similarly, the Colombian study revealed the same result as there was no difference between HPV knowledge and gender[25]. A potential limitation that should be considered when interpreting this study is that the information obtained was collected using a self-administered questionnaire so there is a possibility that some respondents may have given incorrect information. In addition, we didn't use a preestablished validated questionnaire nor any cognitive testing or focus groups to assess the impact of GW on individuals

\section{CONCLUSION}

In conclusion, the commonest type of non-genital warts is hand warts, the level of awareness and knowledge of genital warts and HPV infection among undergraduate students at the Polytechnic University of Sulaimani city was generally very low. The results of this study revealed a poor understanding among respondents about the health problems associated with HPV, its vaccination and modes of transmission. We believe that this study could serve as a useful guide to improve future implementations and policies to increase awareness of HPV infection among students.

\section{Acknowledgment}

The authors would like to thank all colleges of Sulaimani Polytechnic University and participant's students for their cooperation and help in completing this study.

\section{REFERENCE}

[1] D. R. Brown, J. M. Schroeder, J. T. Bryan, M. H. Stoler, and K. H. Fife, "Detection of multiple human papillomavirus types in Condylomata acuminata lesions from otherwise healthy and immunosuppressed patients," J Clin Microbiol, vol. 37, pp. 331622, Oct 1999.

[2] S. K. Loo and W. Y. Tang, "Warts (non-genital)," BMJ Clin Evid, vol. 2009, 2009.

[3] T. Meyer, R. Arndt, E. Christophers, E. R. Beckmann, S Schroder, L. Gissmann, et al., "Association of rare human papillomavirus types with genital premalignant and malignant lesions," J Infect Dis, vol. 178, pp. 252-5, Jul 1998.

[4] L. E. Manhart and L. A. Koutsky, "Do condoms prevent genital HPV infection, external genital warts, or cervical neoplasia?: A meta-analysis," Sexually transmitted diseases, vol. 29, pp. 725735, 2002.

[5] I. Lombard, A. Vincent-Salomon, P. Validire, B. Zafrani, A. de la Rochefordiere, K. Clough, et al., "Human papillomavirus genotype as a major determinant of the course of cervical cancer," J Clin Oncol, vol. 16, pp. 2613-9, Aug 1998.

[6] M. A. Stanley, "Genital human papillomavirus infections: current and prospective therapies," J Gen Virol, vol. 93, pp. 681-91, Apr 2012.

[7] K. A. Ault, "Human papillomavirus vaccines and the potential for cross-protection between related HPV types," Gynecologic oncology, vol. 107, pp. S31-S33, 2007.

[8] L. Koutsky, "Epidemiology of genital human papillomavirus infection," Am J Med, vol. 102, pp. 3-8, May 51997.

[9] B. Suligoi, G. Vittori, M. C. Salfa, L. Timelli, D. Corsini, G. Fattorini, et al., "Prevalence and incidence of external genital warts in a sample of Italian general female population," BMC infectious diseases, vol. 17, p. 126, 2017.

[10] D. R. Brown, S. K. Kjaer, K. Sigurdsson, O. E. Iversen, M. Hernandez-Avila, C. M. Wheeler, et al., "The impact of quadrivalent human papillomavirus (HPV; types 6, 11, 16, and 18) L1 virus-like particle vaccine on infection and disease due to oncogenic nonvaccine HPV types in generally HPV-naive women aged 16-26 years," J Infect Dis, vol. 199, pp. 926-35, Apr 12009.

[11] S. S. Ghadgepatil, S. Gupta, and Y. K. Sharma, "Clinicoepidemiological Study of Different Types of Warts," Dermatol Res Pract, vol. 2016, p. 7989817, 2016.

[12] C. C. Makwe, R. I. Anorlu, and K. A. Odeyemi, "Human papillomavirus (HPV) infection and vaccines: knowledge, attitude and perception among female students at the University of Lagos, Lagos, Nigeria," J Epidemiol Glob Health, vol. 2, pp. 199-206, Dec 2012

[13] H. Baer, S. Allen, and L. Braun, "Knowledge of human papillomavirus infection among young adult men and women: implications for health education and research," J Community Health, vol. 25, pp. 67-78, Feb 2000.

[14] M. A. Gerend and Z. F. Magloire, "Awareness, knowledge, and beliefs about human papillomavirus in a racially diverse sample of young adults," Journal of Adolescent Health, vol. 42, pp. 237242, 2008.

[15] Y. Y. Tan, R. Hesham, and H. M. Qodriyah, "Knowledge and attitude of university students in health sciences on the prevention of cervical cancer," Med J Malaysia, vol. 65, pp. 53-7, Mar 2010.

[16] Y. Tan, R. Hesham, and H. Qodriyah, "Knowledge and attitude of university students in health sciences on the prevention of cervical cancer," Medical Journal of Malaysia, vol. 65, pp. 5357, 2010. 
[17] T. M. Khan, M. A. Buksh, I. U. Rehman, and A. Saleem, "Knowledge, attitudes, and perception towards human papillomavirus among university students in Pakistan," Papillomavirus Research, vol. 2, pp. 122-127, 2016.

[18] L. A. Marlow, G. D. Zimet, K. J. McCaffery, R. Ostini, and J. Waller, "Knowledge of human papillomavirus (HPV) and HPV vaccination: an international comparison," Vaccine, vol. 31, pp. 763-769, 2013.

[19] H.-H. Wang and S.-Y. Wu, "HPV vaccine knowledge and perceived risk of cervical cancer among female college students in Taiwan," Asian Pacific Journal of Cancer Prevention, vol. 14, pp. 7371-7374, 2013.

[20] M. Piñeros, G. Hernández-Suárez, L. Orjuela, J. C. Vargas, and G. Pérez, "HPV knowledge and impact of genital warts on self esteem and sexual life in Colombian patients," BMC Public Health, vol. 13, p. 272, 2013.

[21] S. M. Sherman, E. Nailer, C. Minshall, R. Coombes, J. Cooper, and C. W. Redman, "Awareness and knowledge of HPV and cervical cancer in female students: A survey (with a cautionary note)," J Obstet Gynaecol, vol. 36, pp. 76-80, 2016.

[22] K. Rajiah, M. K. Maharajan, N. S. Chin, and K. S. F. Num, "Awareness and acceptance of human papillomavirus vaccination among health sciences students in Malaysia," VirusDisease, vol. 26, pp. 297-303, 2015.

[23] E. M. Donadiki, R. Jimenez-Garcia, V. Hernandez-Barrera, P. Carrasco-Garrido, A. Lopez de Andres, I. Jimenez-Trujillo, et al., "Knowledge of the HPV vaccine and its association with vaccine uptake among female higher-education students in Greece," Hum Vaccin Immunother, vol. 9, pp. 300-5, Feb 2013.

[24] N. B. Kwang, C. M. Yee, L. P. Shan, C. K. Teik, K. N. Chandralega, and A. Abdul Kadir, "Knowledge, perception and attitude towards human papillomavirus among pre-university students in Malaysia," Asian Pac J Cancer Prev, vol. 15, pp. 9117-9123, 2014.

[25] M. Piñeros, G. Hernández-Suárez, L. Orjuela, J. C. Vargas, and G. Pérez, "HPV knowledge and impact of genital warts on self esteem and sexual life in Colombian patients," BMC Public Health, vol. 13, p. 272, 2013. 